\title{
Targeted treatment of iron deficiency in prolonged critical illness: an opportunity to improve survival or not?
}

\author{
Jan Gunst ${ }^{1^{*}}$ (D) Greet Van den Berghe ${ }^{1}$ (iD and Michael P. Casaer ${ }^{1}$ (D)
}

\section{Dear editor,}

Lasocki et al. recently reported the results of the Hepcidane randomized controlled trial (RCT), randomizing long-stay intensive care unit (ICU) patients to hepcidinguided treatment of iron deficiency versus standard care [1]. Although the intervention had no impact on the primary endpoint-post-ICU length of stay (LOS) - it apparently improved survival, a secondary endpoint. A subgroup analysis, comparing all control group patients with low hepcidin versus those in the intervention group with low hepcidin and effective supplementation (49\%), confirmed a potential survival benefit. The authors should be commended for having performed this landmark RCT, investigating individualized therapy.

Translation of these findings into clinical practice, however, requires important information that is actually lacking. Indeed, the authors evaluated the effect of the intervention on the morbidity and mortality after ICU-discharge, hereby ignoring a potential effect occurring between randomization and discharge. Although patients were randomized shortly before ICU-discharge, the-unreported-time from randomization to discharge might be not negligible, since 12 patients died in this period (more in the intervention group). Likewise, in the Kaplan-Meier curves, the starting point is

This comment refers to the article available online at https://doi.org/10.1186/ s13054-020-03430-3.

\footnotetext{
*Correspondence: jan.gunst@kuleuven.be

${ }^{1}$ Clinical Department and Laboratory of Intensive Care Medicine,

Department of Cellular and Molecular Medicine, KU Leuven, Herestraat 49, 3000 Leuven, Belgium

Full list of author information is available at the end of the article
}

ICU-discharge (day 0), hereby excluding early deaths. The numbers at risk reported under these curves suggest that early deaths were equally excluded from the comparison of 90-day mortality rates. In addition, 3 patients who were exposed to the intervention were excluded because of previously unnoticed exclusion criteria, precluding intention-to-treat analysis. Could the authors report the hospital LOS, mortality rates and Kaplan-Meier curves from randomization onward in all randomized patients and in subgroup analysis?

Second, it appears as if the primary endpoint was unknown in a considerable number of patients. Indeed, patients with missing data were arbitrary assigned LOS of 90 days. Does the 75th percentile of LOS -90 days in both study groups- reflect missing primary outcome data in more than one quarter of patients? Could the authors report the number of missing primary outcome data and repeat the univariate comparison without imputation (although it is unclear if missing data occurred at random or not)?

Third, more than 1800 patients were excluded for unclear reasons. Could the authors specify the reasons, which would provide more insight in the included study population?

Finally, could the authors repeat the subgroup analysis independent of iron supplementation provided/ omitted when indicated, as such is likely not a random phenomenon.

Undoubtedly, these additional data will allow to better appreciate the generalizability of the results of this important RCT.

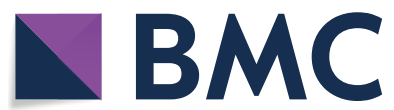

(c) The Author(s) 2021. Open Access This article is licensed under a Creative Commons Attribution 4.0 International License, which permits use, sharing, adaptation, distribution and reproduction in any medium or format, as long as you give appropriate credit to the original author(s) and the source, provide a link to the Creative Commons licence, and indicate if changes were made. The images or other third party material in this article are included in the article's Creative Commons licence, unless indicated otherwise in a credit line to the material. If material is not included in the article's Creative Commons licence and your intended use is not permitted by statutory regulation or exceeds the permitted use, you will need to obtain permission directly from the copyright holder. To view a copy of this licence, visit http://creativecommons.org/licenses/by/4.0/. The Creative Commons Public Domain Dedication waiver (http://creativeco mmons.org/publicdomain/zero/1.0/) applies to the data made available in this article, unless otherwise stated in a credit line to the data. 


\section{Authors' response}

Yes, targeted treatment of iron deficiency may improve critically ill patients survival!

\section{Sigismond Lasocki ${ }^{2}$}

\section{*Correspondence: sigismond@lasocki.com}

2Département Anesthésie Réanimation, Université D'Angers,

CHU Angers, 4 rue Larrey, 49933 Angers Cedex 9, France

Gunst et al. raised several points regarding the results of our Hepcidane trial [1]. The first one concerns the delay between randomization and ICU discharge. Indeed, we initially planned to included patients about to be discharged (i.e. on the day discharge was decided) [2], but we faced logistical problem (the centralized measurement of hepcidin was available only on Thursdays) so patients had to be screened on Mondays and Tuesdays, to have their blood samples drawn on Wednesdays. This explains why some patients had complications and remained in the ICU after inclusion (12 (2.9\%) died during this period). However, the delay between study inclusion and ICU discharge was equivalent in the two groups (medians [Q1-Q3], 2 [1-6] vs 2 [1-6] days), it is the same for the post-randomization length of stay (36 [15-90] vs 36 [15-90] days). Three patients had to be excluded after randomization for unnoticed exclusion criteria ( 2 in control and 1 in intervention arm, respectively) and 1 patient withdrew his consent in the intervention group. These patients were therefore not followed up (2 in each group, see flowchart in Fig. 1 of the article). As indicated in the Table 2 of the manuscript, in intention-to-treat analysis $(n=399$ patients, taking into account the patients dead

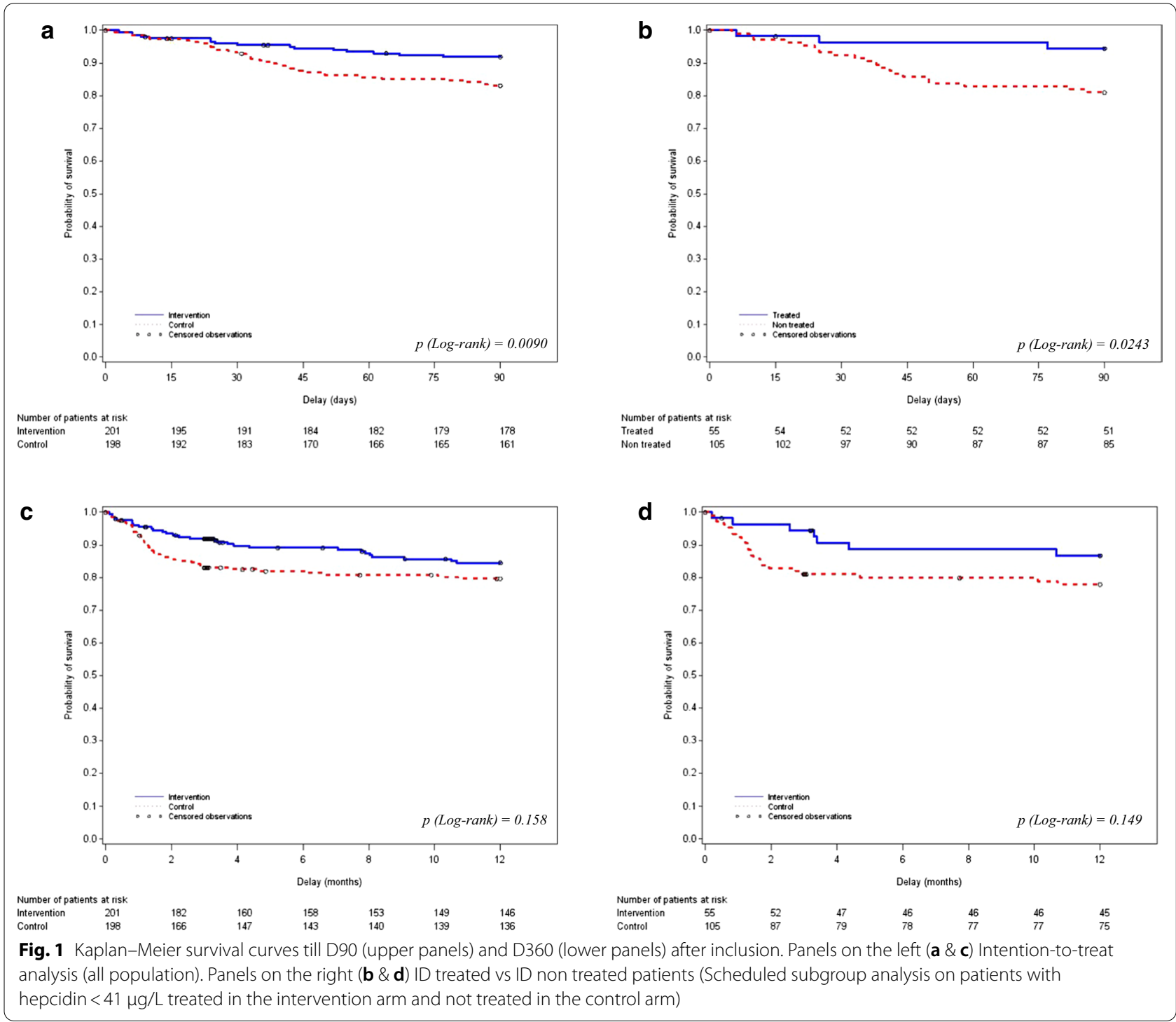


in the ICU) the death rate at D90 was lower in the intervention than in the control arm (16 (8.0\%) vs $33(16.7 \%)$ deaths, $p=0.008)$. This mortality rate was also lower in patients with iron deficiency (ID) treated in the intervention arm compared to those with ID not treated patients in the control arm (subgroup analysis) at D90 (3 (5.45\%) deaths among 55 patients vs 20 (19.05\%) among 105 patients, $p=0.02$ ). The Kaplan Meier survival curves from inclusion till D90 (as initially scheduled in the statistical plan) and till D360 (as requested by reviewers) are reported in the figure.

As indicated in the flowchart of the study, the followup data for length of stay was unknown for only 11 patients, i.e. $2.8 \%$ of the study population. A sensitivity analysis excluding these patients did not find any difference between the two study arms.

We do not know the reason for the non-inclusion of these 1800 patients; however, it is mainly related to the inclusion window limited at 2 days in the week, and also to competing studies: Patients were eligible only at the end of their ICU stay, and many of them were already included in other studies, preventing their inclusion in the Hepcidane trial.

Finally, we compared patients with ID treated or not [2], but it does not make much sense to compare patients with ID (treated or not in the intervention arm) to patients with ID not treated, since it is the treatment of ID that is supposed to be beneficial.

We hope that we have answered the questions, but we fully agree that our study provides only some signal in favor of the treatment of ID based on hepcidin quantification, which need to be confirmed.

\section{Acknowledgements}

Not applicable.

\section{Authors' contributions}

$J G$ wrote the first draft, which was revised by MPC and GVdB. All authors read and approved the final manuscript.
Funding

$J$ G and MPC receive a postdoctoral research fellowship from the University Hospitals Leuven and the Research Foundation - Flanders (Grant No. $1832817 \mathrm{~N}$ ), respectively, and C2 project funding from KU Leuven (Grant No. C24/17/070). GVdB holds an ERC Advanced grant (AdvG-2017-785809) from the Horizon 2020 Program of the EU and receives long-term structural funding from the Methusalem Program of the Flemish Government (METH/14/06).

Availability of data and materials

Not applicable.

\section{Declarations}

Ethics approval and consent to participate

Not applicable.

Consent for publication

Not applicable.

Competing interests

The authors declare that they have no competing interests.

Received: 12 March 2021 Accepted: 27 April 2021

Published online: 01 June 2021

\section{References}

1. Lasocki S, Asfar P, Jaber S, Ferrandiere M, Kerforne T, Asehnoune K, Montravers P, Seguin P, Peoc'h K, Gergaud S, et al. Impact of treating iron deficiency, diagnosed according to hepcidin quantification, on outcomes after a prolonged ICU stay compared to standard care: a multicenter, randomized, single-blinded trial. Crit Care. 2021:25(1):62.

2. Lasocki S, Puy H, Mercier G, Lehmann S, Hepcidane study g. Impact of iron deficiency diagnosis using hepcidin Mass Spectrometry dosage methods on hospital stay and costs after a prolonged ICU stay: study protocol for a multicentre, randomised, single-blinded medico-economic trial. Anaesth Crit Care Pain Med. 2017;36(6):391-6.

\section{Publisher's Note}

Springer Nature remains neutral with regard to jurisdictional claims in published maps and institutional affiliations.

\footnotetext{
Ready to submit your research? Choose BMC and benefit from:

- fast, convenient online submission

- thorough peer review by experienced researchers in your field

- rapid publication on acceptance

- support for research data, including large and complex data types

- gold Open Access which fosters wider collaboration and increased citations

- maximum visibility for your research: over 100M website views per year

At BMC, research is always in progress.

Learn more biomedcentral.com/submissions
} 